\title{
Myoepithelial Cell Differentiation Markers in Ductal Carcinoma in Situ Progression
}

\author{
Tanya D. Russell, ${ }^{*}$ Sonali Jindal, ${ }^{\dagger}$ Samiat Agunbiade, ${ }^{*}$ Dexiang Gao, ${ }^{\ddagger}$ Megan Troxell,,${ }^{\S}$ Virginia F. Borges, ${ }^{* \|}$ and
} Pepper Schedin $* \uparrow$

From the Division of Medical Oncology* and the Department of Pediatrics, ${ }^{\ddagger}$ School of Medicine, University of Colorado Anschutz Medical Campus, Aurora, Colorado; the Departments of Cell, Developmental and Cancer Biology ${ }^{\dagger}$ and Pathology, ${ }^{\S}$ and the Knight Cancer Institute, ${ }^{\top}$ Oregon Health \& Science University, Portland, Oregon; and the University of Colorado Cancer Center," Aurora, Colorado

\author{
Accepted for publication \\ July $21,2015$. \\ Address correspondence to \\ Pepper Schedin, Ph.D., Depart- \\ ment of Cell, Developmental \\ and Cancer Biology, Oregon \\ Health \& Science University, \\ 3181 S.W. Sam Jackson Park \\ Rd., Mailing Code L215, Port- \\ land, OR 97239. E-mail: \\ schedin@ohsu.edu.
}

\begin{abstract}
We describe a preclinical model that investigates progression of early-stage ductal carcinoma in situ (DCIS) and report that compromised myoepithelial cell differentiation occurs before transition to invasive disease. Human breast cancer MCF10DCIS.com cells were delivered into the mouse mammary teat by intraductal injection in the absence of surgical manipulations and accompanying wound-healing confounders. DCIS-like lesions developed throughout the mammary ducts with full representation of human DCIS histologic patterns. Tumor cells were incorporated into the normal mammary epithelium, developed ductal intraepithelial neoplasia and DCIS, and progressed to invasive carcinoma, suggesting the model provides a rigorous approach to study early stages of breast cancer progression. Mammary glands were evaluated for myoepithelium integrity with immunohistochemical assays. Progressive loss of the myoepithelial cell differentiation markers p63, calponin, and $\alpha$-smooth muscle actin was observed in the mouse myoepithelium surrounding DCISinvolved ducts. p63 loss was an early indicator, calponin loss intermediate, and $\alpha$-smooth muscle actin a later indicator of compromised myoepithelium. Loss of myoepithelial calponin was specifically associated with gain of the basal marker p63 in adjacent tumor cells. In single time point biopsies obtained from 16 women diagnosed with pure DCIS, a similar loss in myoepithelial cell markers was observed. These results suggest that further research is warranted into the role of myoepithelial cell p63 and calponin expression on DCIS progression to invasive disease. (Am J Pathol 2015, 185: 3076-3089; http://dx.doi.org/10.1016/j.ajpath.2015.07.004)
\end{abstract}

Clinical evidence is compelling for histologic progression of breast cancer through atypical hyperplasia, ductal carcinoma in situ (DCIS), invasive ductal carcinoma, and metastatic stages. ${ }^{1}$ Such histopathologic progression studies and mutational profiling of epithelial cancers ${ }^{2,3}$ suggest that acquisition of invasive potential is a relatively late event. However, genomic data analyses have revealed that most tumor cell gene expression changes occur at the transition from normal to DCIS, with few additional changes in expression occurring at the transition from DCIS to overt invasive disease. ${ }^{4,5}$ These observations implicate key roles for nonepithelial cells in progression to invasive disease. ${ }^{6,7}$ The lack of relevant model systems has hindered our understanding of the DCIS to invasive transition.
The clinical definition of invasive breast cancer is spread of malignant tumor cells from the confines of the mammary duct into the adjacent tissue stroma. In the normal mammary gland, epithelial ductal and alveolar structures are

Supported by an NIH T32 Training grant "Training in Pharmacology of Antineoplastic Agents" (Division of Medical Oncology, University of Colorado Anschutz Medical Campus); the Thorkildsen Research Fellowship (University of Colorado Anschutz Medical Campus), a UNCF Merck Postdoctoral Science Research Fellowship, and a Department of Defense Postdoctoral Award BC096776 (T.D.R.); NIH/National Cancer Institute grant R01CA169175, the Avon Foundation, and the Grohne Family Foundation (P.S. and V.F.B.); and the Tissue Biobanking and Processing Shared Resource of Colorado's NIH/NCI Cancer Center Support grant P30CA046934.

T.D.R. and S.J. contributed equally to this work

Disclosures: None declared. 
surrounded by a contractile myoepithelial cell layer that facilitates milk expulsion during lactation. ${ }^{8}$ The mammary myoepithelial cells are also required for normal mammary gland development, because they influence epithelial cell polarity, ductal branching, and milk production. ${ }^{8} \mathrm{~A}$ hallmark of progression from DCIS to invasive cancer is physical breach of the myoepithelial cell layer and underlying basement membrane. For tumor progression, studies suggest that myoepithelial cells play an active role in tumor suppression by secreting protease inhibitors, downregulating matrix metalloproteinases,,${ }^{9,10}$ and producing tumor suppressive proteins such as maspin, p63, Wilms tumor 1 , and laminin $1 .{ }^{11-13}$ These data support the hypothesis that the tumor suppressive function of myoepithelium is lost with DCIS progression, resulting in the transition from preinvasive to invasive cancer. ${ }^{14-16}$ Further studies report that tumor cells adjacent to focally disrupted myoepithelium can display distinct phenotypes, including estrogen receptor negativity, genetic instabilities, increased expression of invasion-related genes, and aberrant E-cadherin expression. ${ }^{17,18}$ Overall, these data support an active role for the myoepithelium in suppressing DCIS progression and implicate loss of this function as critical for the transition to invasive disease.

Invasive potential of human mammary epithelial tumor cell lines is evaluated primarily by injecting cells into the mammary fat pads of immune compromised mice. Although the mammary fat pad is the correct anatomic organ for breast cancer, mammary fat pad models bypass the requirement for tumor cells to exit from the location of their initiation, that is, the mammary ducts. In transgenic models, early-stage disease is intraductal, and these models display tumor progression from ductal intraepithelial neoplasia (DIN) to invasive stages. However, in transgenic models, most epithelial cells contain the active oncogene; thus, these models do not replicate cellular transformation as a relatively rare event. Here, we used an intraductal approach in the absence of surgery, ${ }^{19}$ because this approach offers a key advantage in that cells are directly placed into the mammary ductal system, which is the site of early-stage disease. Importantly, this approach permits modeling of disease progression in the background of a normal mammary epithelium. Further, our nonsurgical approach permits co-evolution of tumor progression with myoepithelial cell changes with minimal wound healing or proinflammatory induction. With this intraductal model, we observed progressive loss of the myoepithelial cell differentiation markers p63, calponin, and $\alpha$-smooth muscle actin ( $\alpha$-SMA) before tumor cell breach of the myoepithelium. Further, myoepithelial cell loss of calponin strongly associates with gain of p63 expression in adjacent epithelial tumor cells, a marker of basal epithelium. These studies identify compromised myoepithelial cell function before transition to invasive disease and suggest that disrupted myoepithelial expression of calponin may predict DCIS-involved ducts at risk of progression to invasive disease.

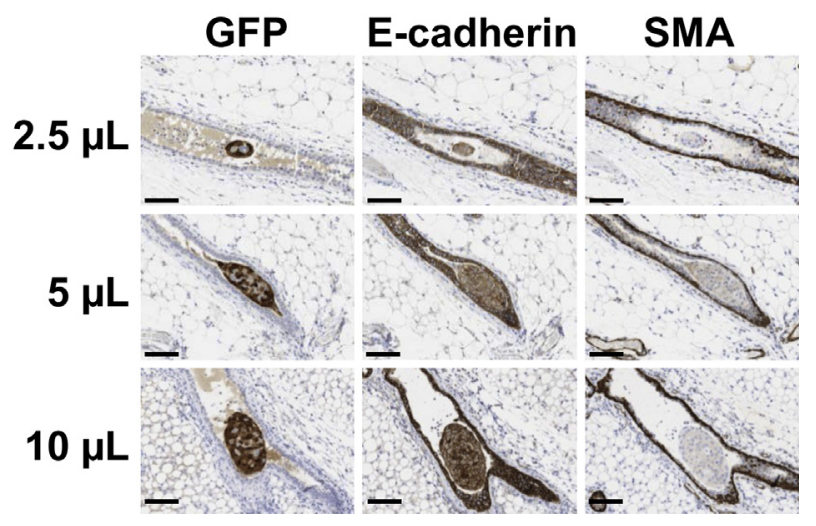

Figure 1 Ductal and myoepithelial cell layer integrity are not compromised by the intraductal injection method. GFP-labeled MCF10DCIS.com cells were injected at volumes of 2.5, 5.0, and $10 \mu \mathrm{L}$ to assess junctional complex and myoepithelial cell layer disruption at 24 hours after injection. Serial sections were stained with GFP to confirm the presence of human tumor cells (brown), E-cadherin to assess ductal epithelial junctional complex disruption (brown), and $\alpha$-SMA to assess myoepithelial cell layer disruption (brown). Images were scanned with Aperio software; digital resolution $=0.25 \mu \mathrm{m}$ per pixel. Scale bar $=100 \mu \mathrm{m}$. GFP, green fluorescent protein; $\alpha$-SMA, $\alpha$-smooth muscle actin.

\section{Materials and Methods}

\section{Cell Culture}

Human triple-negative breast cancer MCF10DCIS.com cells and green fluorescent protein (GFP)-labeled MCF10DCIS.com cells, generous gifts from Fred Miller and Kornelia Polyak, were cultured as previously described, ${ }^{10}$ trypsinized, and resuspended in phosphate-buffered saline immediately before injection. Cells were used between passages 8 to 22 , because passages later than 22 were shown to display a more invasive phenotype. ${ }^{20} \mathrm{~T} 47 \mathrm{D}$, MCF7, and HCC70 cells were obtained from the University of Colorado Cancer Center Protein Production/Mab/Tissue Culture Core and cultured as recommended by the supplier.

\section{Animals and Intraductal Injections for Tumor Studies}

Five-week-old female nulliparous severe combined immunodeficient mice were obtained from Taconic (Hudson, NY) and maintained in the Center for Laboratory Animal Care at the University of Colorado Anschutz Medical Campus. For intraductal injections of human breast cancer cells, mice were anesthetized with isoflurane. Depending on experiment, 2.5 to $10 \mu \mathrm{L}$ of 50,000 MCF10DCIS.com, T47D, MCF7, or HCC70 cells were intraductally injected into anesthetized mice with the use of a previously described intraductal delivery method developed for viral delivery. ${ }^{19,21}$ Briefly, a $25-\mu \mathrm{L}$ Wiretrol II disposable glass micropipette (no. 5-000-2050; Drummond Scientific Company, Broomall, PA) was drawn and firepolished into a fine tip of 60 to $75 \mu \mathrm{m}$. Sterile cell solution was back-loaded into the micropipette with a stainless steel plunger. With the use of a micromanipulator, the pipette tip was gently inserted directly into the teat canal, and cells were slowly ejected into the lumens of the third thoracic and fourth inguinal mammary glands of mice $(n=3$ to 4 injected glands 

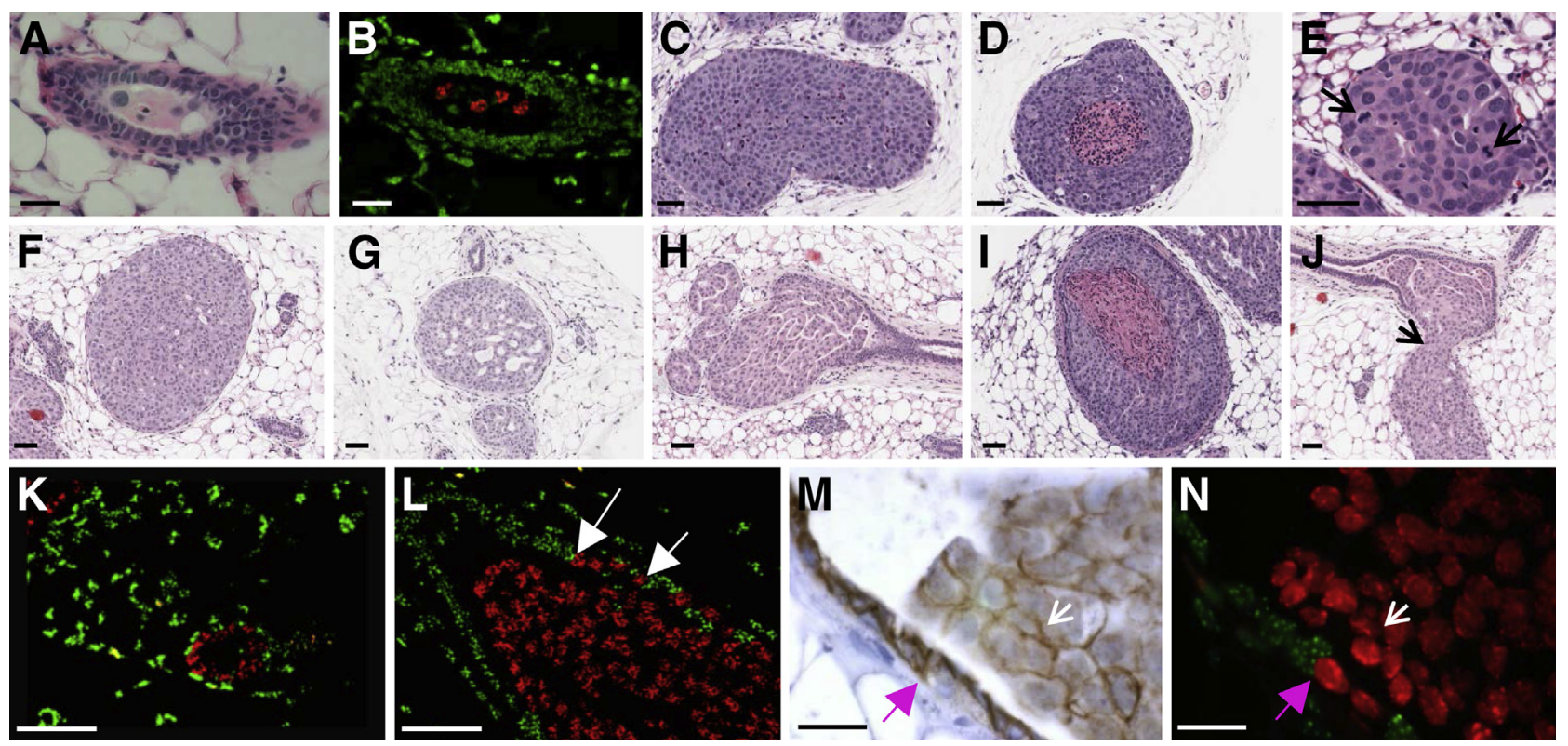

Figure 2 Assessment of tumor cell lines injected via the mammary intraductal model. Serial H\&E (A) and FISH analyses for human (red) and mouse (green) COT-1 DNA (B) of nulliparous mouse mammary glands injected with T47D breast tumor cells in the absence of estradiol via intraductal method. H\&E images from MCF7 cells intraductally injected in the presence of estradiol display the solid (C) and comedo (D) characteristics of human DCIS and solid DCIS from HCC70 tumor cells (E) with high mitotic activity (E, arrows). H\&E analysis of MCF10DCIS.com tumor cells injected via mammary intraductal method display characteristics of human DCIS (solid, F; cribriform, G; papillary, H; comedo, I), and invasive lesions (J, arrow). FISH analysis for human (red) and mouse (green) COT-1 DNA reveals tumor progression from normal-like ductal structures (K) to DCIS (L) with incorporation of human tumor cells into normal mouse mammary ducts (white arrows). Serial IHC analyses of E-cadherin (M) (brown) and FISH (N) suggest that E-cadherin-based junctional complexes form between MCF10DCIS.com cells and mouse ductal epithelial cells (purple arrows) and between neighboring MCF10DCIS.com cells (white arrows). Brightfield images were scanned with Aperio software; digital resolution $=0.25 \mu \mathrm{m}$ per pixel. Scale bars: $80 \mu \mathrm{m}(\mathbf{E}-\mathbf{J}) ; 50 \mu \mathrm{m}(\mathbf{K}$ and $\mathbf{L}) ; 20 \mu \mathrm{m}(\mathbf{M}$ and $\mathbf{N})$. DCIS, ductal carcinoma in situ; FISH, fluorescence in situ hybridization; H\&E, hematoxylin and eosin; IHC, immunohistochemical.

per mouse). Images depicting the intraductal injection technique were captured with a Canon PowerShot A620 camera with 4X optical zoom (Canon, Tokyo, Japan). For injections with T47D and MCF7 cells, anesthetized mice received a sterile placebo implant (catalog no. SC-111; Innovative Research of America, Sarasota, FL) or a 0.72-mg 17 $\beta$-estradiol slow release implant (catalog no. SE-121; Innovative Research of America). The implant insertion area (dorsal side of neck between the shoulder blades) was shaved and swabbed with chlorhexidine digluconate solution. Pellets were inserted with a sterilized 10-gauge stainless steel precision trocar (catalog no. MP-182; Innovative Research of America). To compare intraductal injection techniques, mammary ducts of two anesthetized mice were surgically exposed as previously reported. ${ }^{22,23}$ At study end, mammary tissue was excised from animals euthanized by carbon dioxide exposure, followed by cervical dislocation. Excised mouse mammary glands were fixed in $10 \%$ neutral buffered formalin for 24 hours and paraffin embedded for histologic and immunologic analyses. All animal procedures were approved by the Institutional Animal Care and Use Committee of the University of Colorado Anschutz Medical Campus [protocols 72110(07)1E and 72112(08)1E].

\section{Human Tissue Acquisition}

Formalin-fixed, paraffin embedded breast tissue obtained from 19 premenopausal women aged 20 to 45 years who underwent clinically indicated surgical treatment were included in the study. For each case multiple blocks were reviewed, and a single representative block was selected for all subsequent analyses. Sixteen of these women were diagnosed with pure DCIS and three had a diagnosis of invasive ductal carcinoma with DCIS component. Ten cases were obtained with approval of the Colorado Multiple Institution Review Board under two protocols. One protocol was a retrospective chart review and tissue collection-only study deemed exempt from subject consent and Health Insurance Portability and Accountability Act (HIPPA) authorization, whereas the other protocol included informed written patient consent. Nine pure DCIS cases were received from Oregon Health Science University under institutional review board protocol with HIPPA waiver. Tissues were sectioned to $4 \mu \mathrm{m}$ and adhered to glass slides for subsequent histologic and immunohistologic analyses. Within these 19 cases, a cumulative number of 234 individual DCIS-involved ducts were analyzed as described in the following section.

\section{Histologic Assessments}

Hematoxylin and eosin-stained slides were used to assess the distribution of tumor emboli, DIN, DCIS, DCIS with microinvasion, and invasive lesions for mouse mammary glands and human breast tissues. For these analyses, hematoxylin and eosin-stained slides were scanned, and total tumor number and area quantified with Aperio Spectrum software (Aperio 


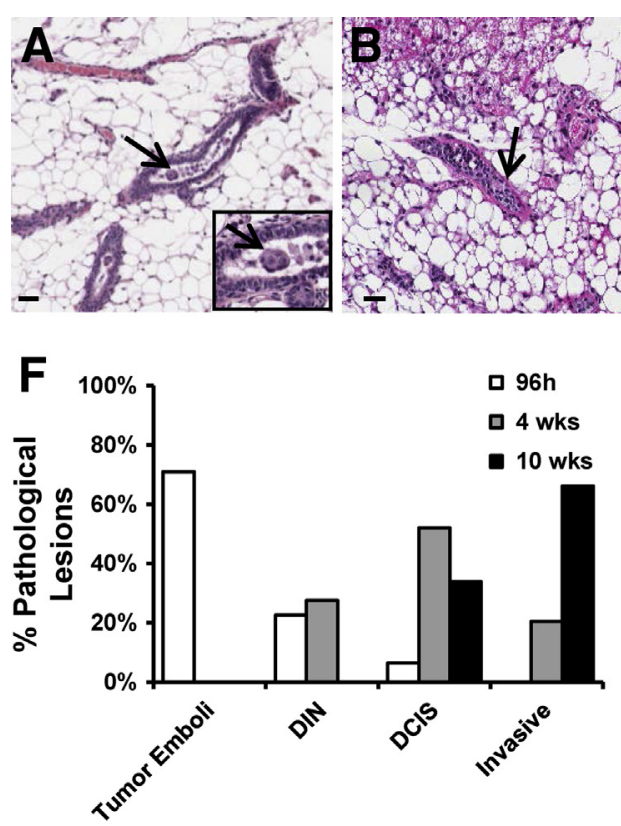

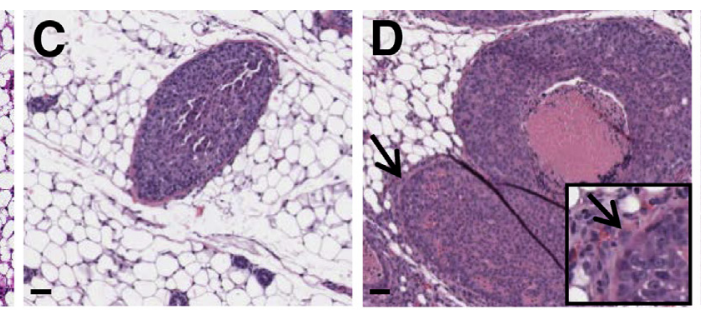

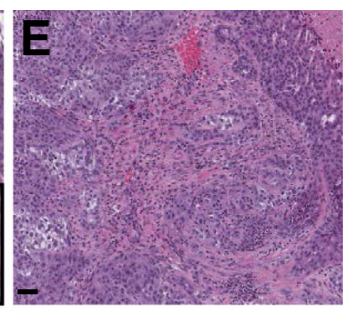

Figure 3 Multifocal tumor progression model assessment. Representative H\&E images of intraductal tumor progression reveal the formation of tumor emboli (A, arrows), DIN (B, arrow), DCIS (C), DCIS with tumor cell escape (D, arrows), and overt invasion (E). Insets in $\mathbf{A}$ and $\mathbf{D}$ are enlarged to show detail. Quantification of each type of pathologic lesion shows tumor progression from mostly tumor emboli at 96 hours after injection, to DCIS at 4 weeks after injection, to invasive cancer at 10 weeks after injection (F). Images were scanned with Aperio software; digital resolution $=0.25 \mu \mathrm{m}$ per pixel. Scale bar $=50 \mu \mathrm{m}$. DCIS, ductal carcinoma in situ; DIN, ductal intraepithelial neoplasia; H\&E, hematoxylin and eosin.
Scanscope Console application version 102.0.0.20.44; Aperio Technologies, Vista, CA). Tumor emboli were defined as one to five layers of tumor cells within mammary ducts that lacked direct contact with the murine mammary epithelium. DINs were described in this study as ducts with two to three layers of malignant cells. ${ }^{24}$ DCIS-involved ducts were assessed for histology subtypes. ${ }^{25}$ DCIS with microinvasion was defined as a lesion with small clusters or single tumor cells outside of the mammary duct in the absence of hematoxylin and eosin evidence for myoepithelial cell loss. ${ }^{25}$ Invasive lesions were defined as lesions with histologic evidence for loss of myoepithelial cells and tumor cells infiltrating the mammary stroma.

\section{Fluorescence in Situ Hybridization Analysis}

Fluorescence in situ hybridization analyses were performed with probes for human and mouse Cot-1 DNA, as previously described, ${ }^{26}$ by the University of Colorado Cancer Center Cytogenetics Core.

\section{Immunohistochemistry}

For immunohistochemistry (IHC), 4- $\mu \mathrm{m}$ sections of paraffin embedded mouse mammary gland and human breast tissues were pretreated with Dako TRS Antigen Retrieval Solution (TRS) or EDTA Antigen Retrieval Solution (EDTA; Dako North America Inc., Carpinteria, CA). The primary antibodies and antibody dilutions were: mouse anti-human E-cadherin (dilution 1:100; TRS; catalog no. 3195; Cell Signaling, Danvers, MA), mouse anti-human p63 (dilution 1:200; EDTA; catalog no. CM163B; BioCare Medical, Concord, CA), CD45 (dilution 1:1000; TRS; catalog no. 550539; BD Pharmingen, San Jose, CA), mouse anti-human cytokeratin 5 (dilution 1:50; EDTA; catalog no. CM 234C; BioCare Medical), rabbit anti-human calponin (dilution 1:800; EDTA; catalog no. ab46794; Abcam, Cambridge, MA), mouse anti-human $\alpha$ SMA (dilution 1:200; EDTA; catalog no. M0851; Dako North America Inc.). Immunoreactivity was detected with Envision + system mouse and rabbit secondary antibodies (catalog nos. K4001 and K4003; Dako North America Inc.) with 3, 3'-diaminobenzidine (catalog no. K3568; Dako North America Inc.) used as the chromogen for all stains. Estrogen receptor positivity was assessed according to the Allred scoring method. ${ }^{27}$ HER2 positivity was determined with the U.S. Food and Drug Administration-approved Hercep test for the Dako Autostainer (catalog no. K5207; Dako North America Inc.).

\section{Immunofluorescent Analysis}

Immunofluorescence multiplex staining was performed on pure DCIS and DCIS lesions from the intraductal mouse model and human cases with the use of primary antibodies to p63 (dilution 1:200; EDTA; catalog no. CM163B; BioCare Medical), calponin (dilution 1:800; EDTA; catalog no. ab46794; Abcam), and $\alpha$-SMA (dilution 1:200; EDTA; catalog no. M0851; Dako North American Inc.), and unlabeled species specific, secondary antibodies (dilution 1:500, and dilution 1:1000; catalog no. 31,461; Thermo Fischer Scientific, Rockford, IL). Multiplex staining was accomplished with OPAL 3-Plex Kit (catalog no. KNEL79100IKT; Perkin Elmer, Waltham MA) for application of Fluorescein Plus, cyanine-5, and cyanine-3 fluorochromes according to the manufacturer's instructions. Nuclei were stained with 0.1 $\mathrm{mg} / \mathrm{mL}$ DAPI (Sigma-Aldrich, St. Louis, MO).

\section{Imaging and Quantification}

Stained slides were scanned with Aperio and Ariol Scanner systems (Leica Biosystems, Richmond IL) at $\times 20$ 
magnification, corresponding to $0.25 \mu \mathrm{m}$ per pixel (Aperio) or $0.32 \mu \mathrm{m}$ per pixel (Ariol), which enables highresolution access to the entire tissue section via a virtual image. Tumor cells were identified on the basis of their structural characteristics, including nuclear pleomorphism, irregularity, and multiple nucleoli. For quantitation of myoepithelial cell differentiation status by IHC, myoepithelial cell expression of $\alpha$-SMA, calponin, and p63 were
SMA

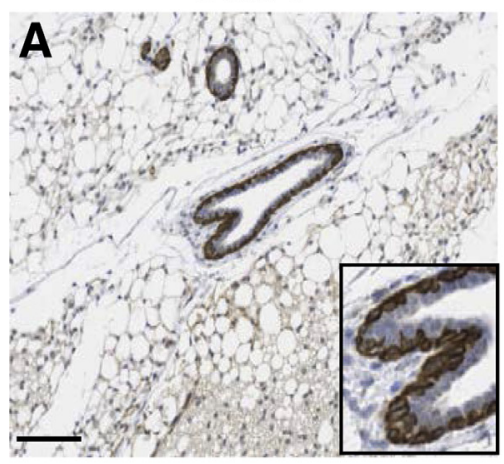

\section{D}
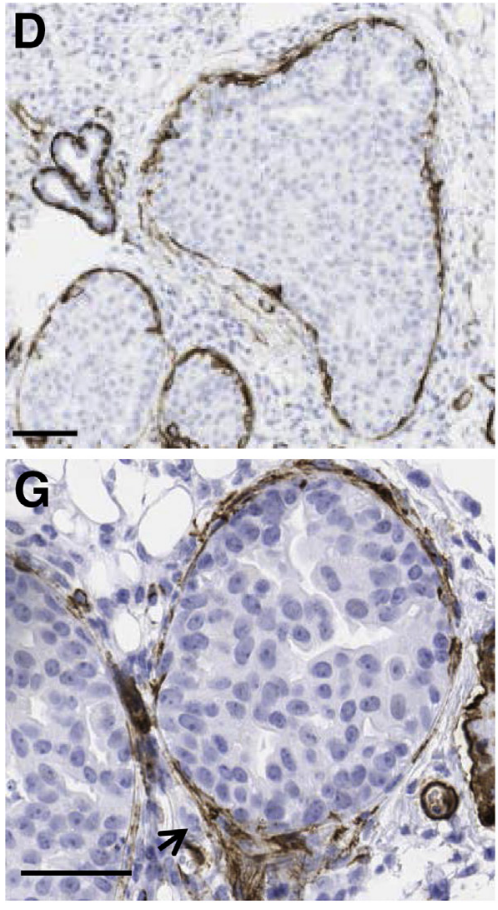

J

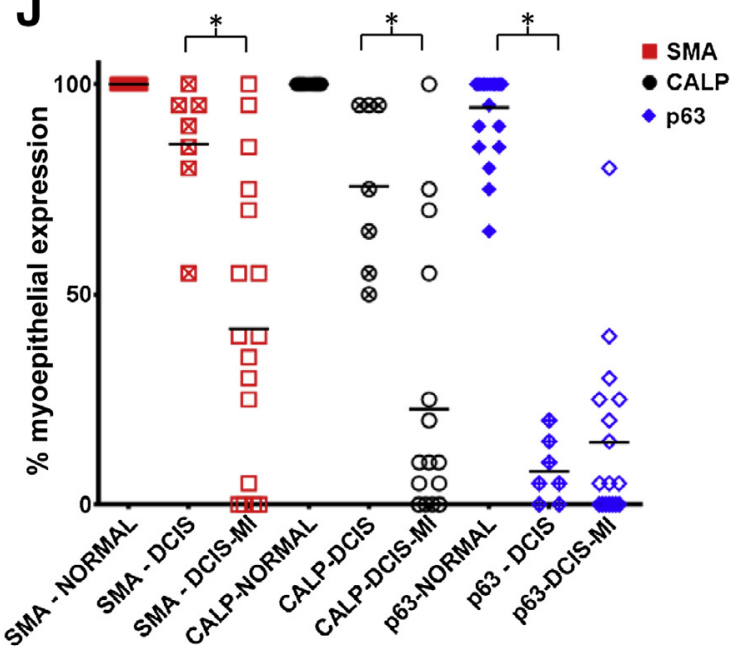

Calponin
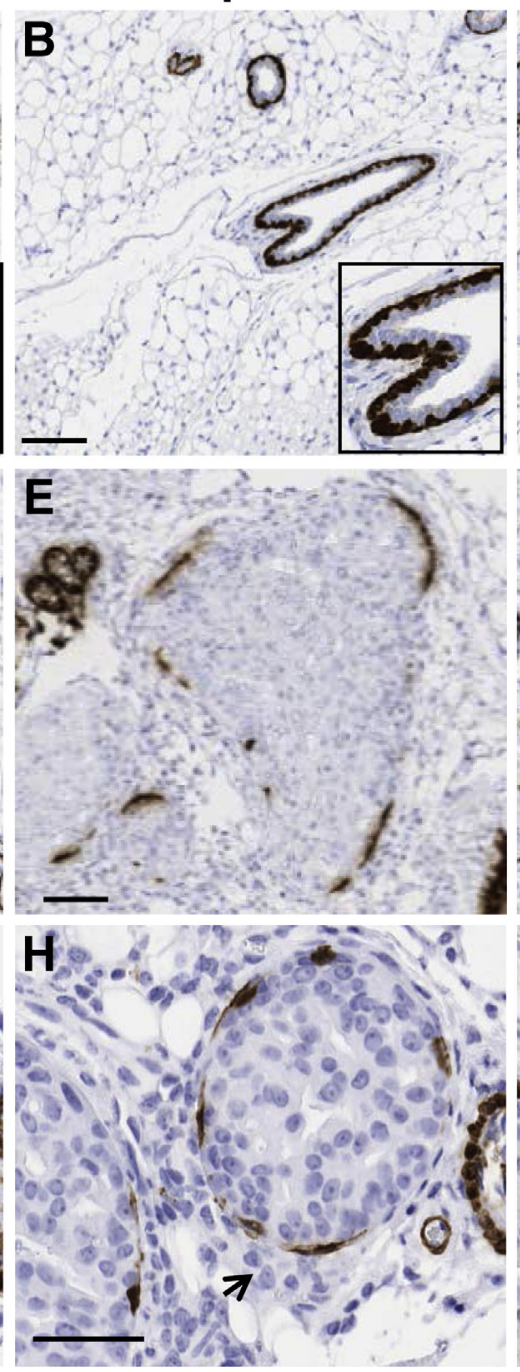

p63
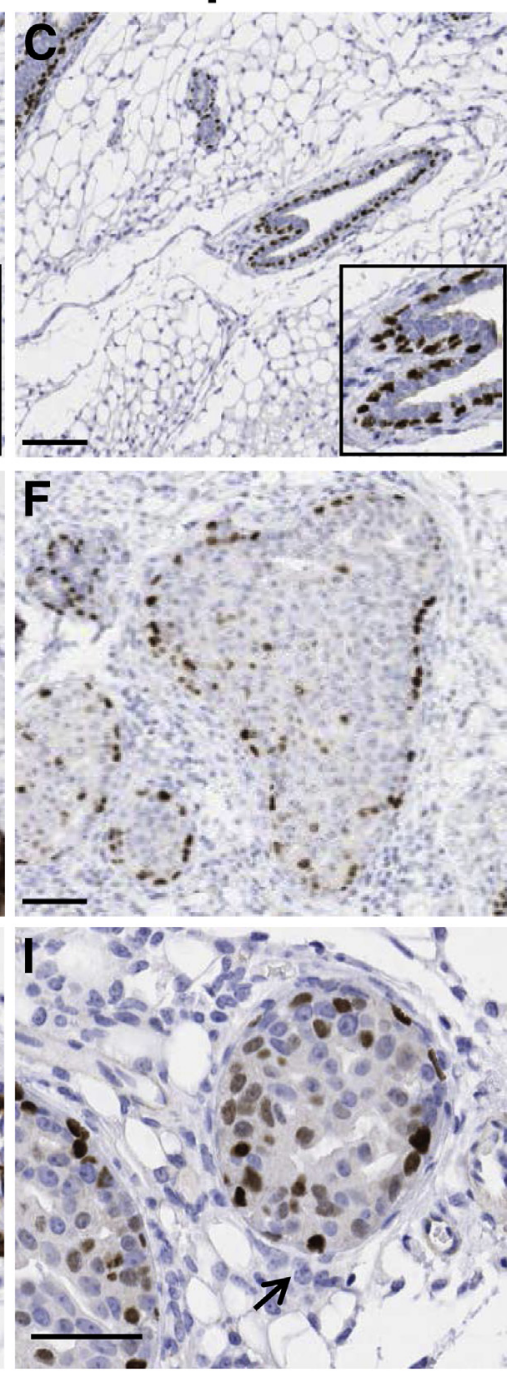

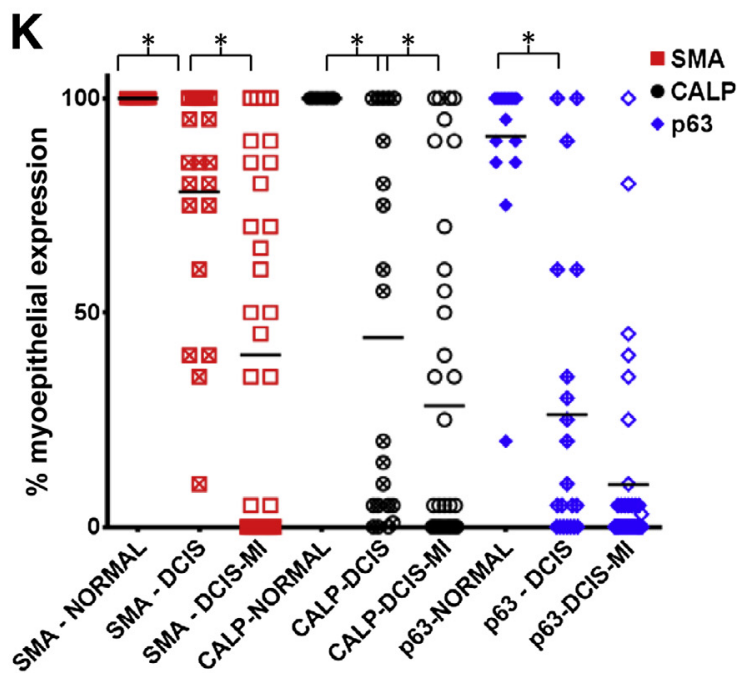


obtained with serial IHC sections from five human cases. The surrounding normal terminal ductal-lobular units served as internal positive controls for these myoepithelial cell differentiation markers. Myoepithelial cell marker positivity is expressed as an average percentage of coverage of ducts with DCIS involvement per time point per group with $\geq 25$ lesions analyzed per group. Data were collected by two independent assessments: histology-based visual assessment and unbiased automated computational deconvolution algorithm (Aperio Deconvolution 9 algorithm version 11.2; Aperio Technologies, Leica Biosystems). Interassessment variation was found to be $<10 \%$. For immunofluorescent image quantitation, we assessed DCIS-involved ducts for the percentage of myoepithelial cells positive for p63, calponin, and $\alpha$-SMA. Because p63 is a nuclear marker, staining is intermittent even in cases when $100 \%$ of the myoepithelial cells are $\mathrm{p} 63$ positive. Thus, in a subset analysis, we quantified the percentage of p63-positive nuclei to total myoepithelial nuclei. Myoepithelial nuclei were defined as small nuclei in cells positive for $\alpha$-SMA and/or calponin on triple immunofluorescence stained slides (Supplemental Figure S1). These nuclear count data were compared with the visual assessments for scoring the percentage of myoepithelial nuclei positive for p63. Method comparisons showed percentage of coverage of $64.4 \%$ by quantitative nuclear counting compared with $63.7 \%$ by qualitative-visual assessments. All subsequent analyses, performed by a pathologist (S.J.), were evaluated by the qualitative-visual method.

\section{Statistical Analysis}

In the mouse model, mixed effects analysis of variance was used to compare normal, DCIS, and invasive ductal carcinoma for each biomarker ( $\alpha$-SMA, calponin, and p63) at 4 and 10 weeks, and to also compare DCIS at 4 weeks versus 10 weeks, and DCIS with microinvasion at 4 weeks versus 10 weeks. Repeated analysis of variance was used to estimate and compare the human DCIS cases. For both mouse and human cases, there were multiple DCIS-involved ducts or tumors from a single individual included in individual analyses. Because DCIS-involved ducts and tumors from the same individual might share similar characteristic, we allowed a random mouse effect (random effect with a normal distribution with mean $=0$ and variance estimated from the data) to account for the possible correlation during the modeling process. Similarly, $P$ value justification for multiple comparisons was performed according to
Bonferroni's approach. $P<0.05$ was considered statistically significant.

\section{Results}

\section{Intraductal Model Preserves Mammary Duct Integrity}

To deliver breast cancer cells to the correct anatomic location for DCIS, we modified a nonsurgical injection model previously developed for intraductal viral delivery. ${ }^{19,21}$ In our model, human triple-negative MCF10DCIS.com cells ${ }^{20}$ are intraductally injected into an intact teat of nulliparous mice in the absence of any surgical manipulation (Supplemental Figure S2, $\mathrm{A}$ and $\mathrm{B}$ ). In a comparison of our intraductal model with one that surgically exposes the mammary duct, we found lower infiltrate of $\mathrm{CD}^{+} 5^{+}$immune cells in the absence of surgery $(P \leq 0.029$, unpaired $t$-test) (Supplemental Figure S2, C-E). This observation suggests that the nonsurgical approach minimizes inflammation as a potential confounder of tumor progression in intraductal breast cancer models; thus for all subsequent studies the nonsurgical tumor cell injection model was used. ${ }^{28-31}$ Because progression to invasive disease requires disruption of normal epithelial junctional integrity and loss of the myoepithelial cell layer, we next verified that ductal integrity was not compromised during intraductal tumor cell delivery. GFP-labeled MCF10DCIS.com cells were injected at 2.5-, 5.0-, or 10- $\mu \mathrm{L}$ volumes. The effect of the different injection volumes 24 hours after injection on the integrity of the epithelial and myoepithelial cell layers was determined by assessing the presence of GFP-labeled cells within the mammary stroma and by IHC detection of ductal epithelial E-cadherin and myoepithelial $\alpha$-SMA. For all three injection volumes, there was no evidence of $\mathrm{GFP}^{+}$tumor cells within the mammary stroma, no visible signs of disruption of the epithelial E-cadherin junctional complexes, and no evidence of disruption in the myoepithelial cell layer (Figure 1). However, whether junctional integrity is functionally compromised in the mammary gland via intraductal injection cannot be fully addressed with IHC. Previous studies have analyzed tight junction permeability of mammary epithelial cells during secretory activation by intraductally injecting ${ }^{14} \mathrm{C}$-sucrose and measuring its presence in the blood. ${ }^{32}$ Thus, we assessed ${ }^{14} \mathrm{C}$-sucrose permeability in nulliparous glands and found that, although injected dye volumes of $5 \mu \mathrm{L}$ do not appear to compromise ductal integrity, volumes of $\geq 10 \mu \mathrm{L}$ may disrupt junctional complexes (Supplemental Figure S2F). Therefore, for subsequent studies, we elected to use a $5-\mu \mathrm{L}$

\footnotetext{
Figure 4 Progressive loss of myoepithelial cell differentiation markers in the intraductal DCIS model. Serial IHC analysis of myoepithelial cell markers $\alpha$-SMA (A, $\mathbf{D}$, and $\mathbf{G}$, brown), CALP (B, E, and $\mathbf{H}$, brown), and p63 (C, F, and I, brown). Normal mouse ductal structures show uniform IHC staining of the myoepithelium (A-C); insets are enlarged to show detail of normal ducts. Variable myoepithelial cell marker coverage is observed in DCIS-involved ducts (D-F) and DCIS-involved ducts with microinvasion (G-I, arrows show tumor cells outside the duct). Gain of p63 by tumor cells is also apparent (F and $\mathbf{I})$. Quantification of the percentage of coverage of myoepithelial cell layer markers surrounding DCIS tumors compared with normal ductal structures at 4 weeks (J) and 10 weeks (K) after tumor cell injection. Statistical significance was determined by mixed effects analysis of variance and $P$ value justification for multiple comparisons using Bonferroni's approach. ${ }^{*} P<0.05$. Solid bars $=$ SEM. Images were scanned with Aperio software; digital resolution $=0.25 \mu \mathrm{m}$ per pixel. Scale bars: $100 \mu \mathrm{m}(\mathbf{A}-\mathbf{F}) ; 50 \mu \mathrm{m}(\mathbf{G}-\mathbf{I})$. CALP, calponin; DCIS, ductal carcinoma in situ; H\&E, hematoxylin and eosin; IHC, immunohistochemical; MI, microinvasion; $\alpha$-SMA, $\alpha$-smooth muscle actin.
} 
volume of tumor cells for intraductal teat injection into nulliparous hosts.

To investigate the ability of our nonsurgical, intraductal tumor cell injection protocol to support growth of additional human breast cancer cell lines, we analyzed tumor formation and progression of two luminal A cell lines, T47D and MCF7, and a second triple-negative cell line, HCC70, at 4 weeks after tumor cell injection. ${ }^{33}$ T47D cells did not form

\section{SMA}
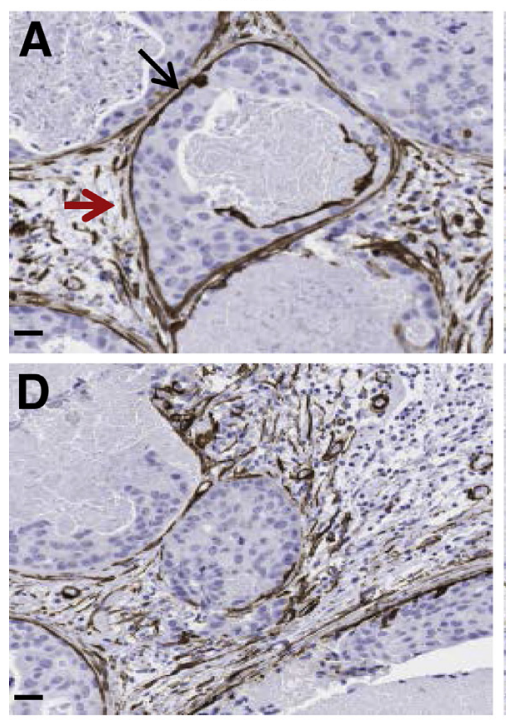

Calponin
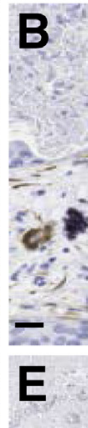
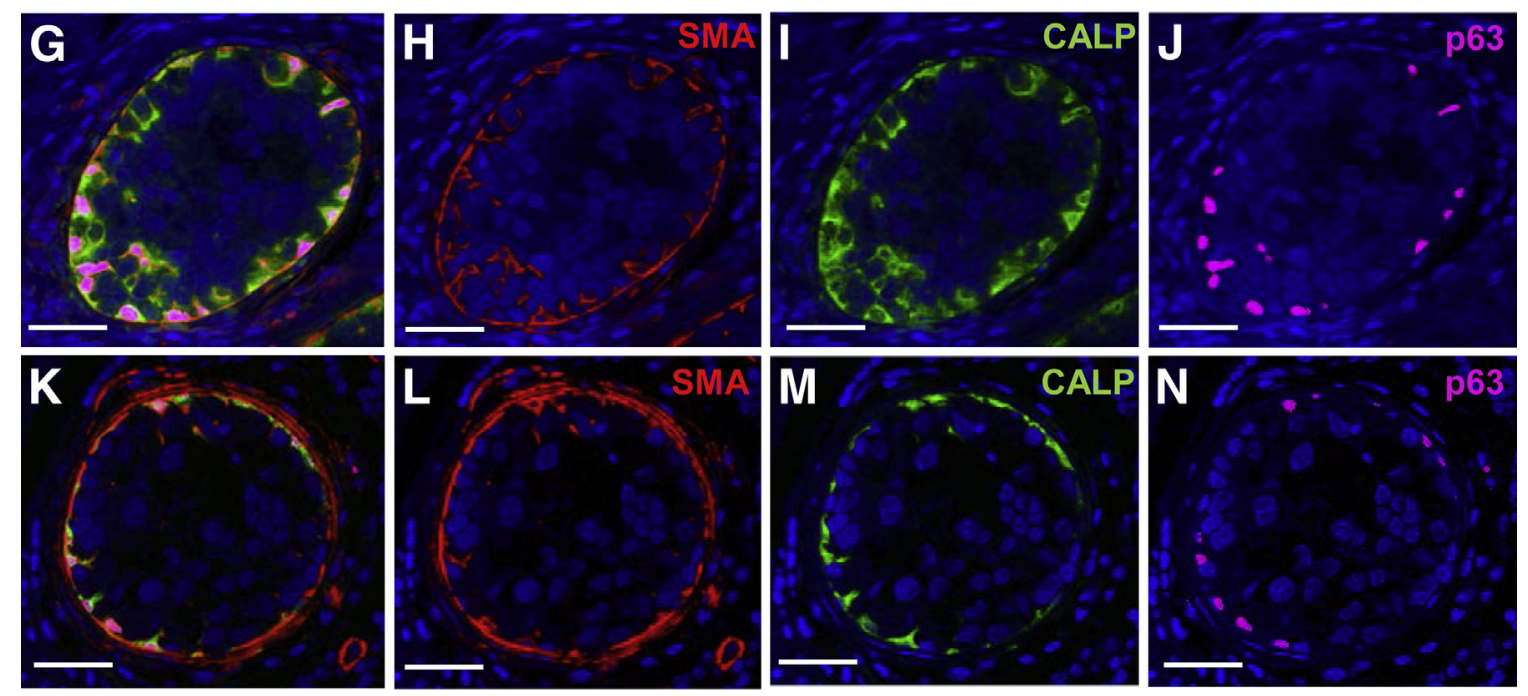

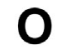

$\mathbf{P}$
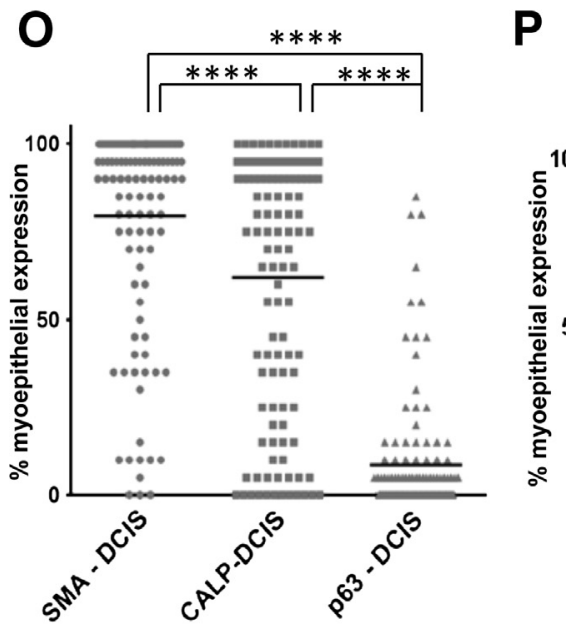
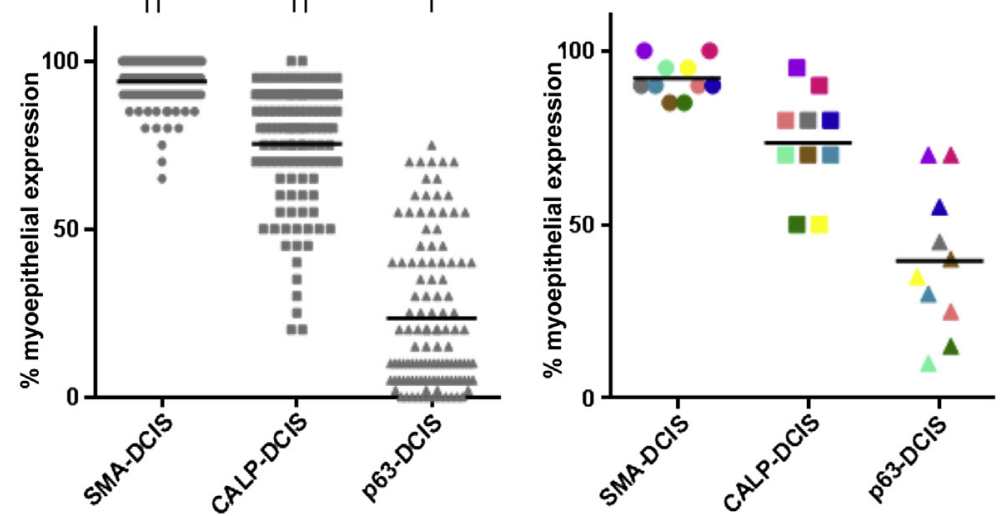
tumors in the absence or presence of supplemental estradiol; however, a few viable tumor cells persisted in mammary lumens at 4 weeks after injection (Figure 2, A and B). MCF7 cells failed to form tumors in the absence of estradiol, but they readily formed solid (Figure 2C) and comedo-like (Figure 2D) DCIS lesions in the presence of supplemental estradiol. The triple-negative HCC70 cell line formed mostly solid DCIS with high mitotic activity (Figure 2E). On the basis of these data, the nonsurgical intraductal model permits the intraductal growth of estrogen receptor-positive and -negative breast cancer cell lines.

\section{Histologic Patterns of Tumor Progression}

Our histologic analysis of MCF10DCIS.com intraductal tumors identified lesions with characteristics of the main human DCIS subtypes: solid, cribriform, papillary, and comedo (Figure 2, $\mathrm{F}-\mathrm{I}$ ), observations that corroborate and extend other intraductal delivery studies. ${ }^{22,23}$ Further, and as observed by others, we found that MCF10DCIS.com cells breach the mouse myoepithelial cell layer and locally invade into the adjacent stroma (Figure 2J). The intraductal MCF10DCIS.com cell lesions use the endogenous mouse myoepithelial layer (Figure 2, K and L) and do not generate a human cell-derived myoepithelial cell layer as observed when this cell line is injected subcutaneous or into the mammary fat pad. ${ }^{10,20,34,35}$ Unique to the intraductal delivery model, we observe that normal ductal structures can be composed primarily of human MCF10DCIS.com cells (Figure $2 \mathrm{~K}$ ) and that tumor cells incorporate into the normal mouse ductal epithelium (Figure 2L), as detected by fluorescent in situ hybridization with the use of probes specific for human (red) and mouse (green) COT-1 DNA. We next evaluated whether MCF10DCIS.com cells form E-cadherin-based adherens junctions with neighboring mouse luminal epithelial cells, suggesting that lesions reminiscent of early-stage tumors develop in this model. E-cadherin staining was consistent with MCF10DCIS.com cells forming E-cadherin-based junctional complexes with normal mouse epithelial cells and with neighboring tumor cells, albeit at a lower staining intensity (Figure 2, $\mathrm{M}$ and $\mathrm{N}$ ). In sum, the intraductal tumor delivery model is poised for the study of tumor cell escape and/or invasion from intact mammary ducts.

To investigate disease progression in this model, we quantified the number of intraductal tumor emboli (Figure 3A), ductal intraepithelial neoplasia (DIN) (Figure 3B), DCISinvolved ducts without or with microinvasion (Figure 3, C and D), and overt invasive lesions (Figure 3E) at 96 hours, 4 weeks, and 10 weeks after tumor cell injection. Tumor cell emboli were predominant at 96 hours after injection, comprising $70 \%$ of the mammary gland lesions, followed by DIN and DCIS-like lesions (Figure 3F). The distribution of lesions shifted from emboli toward DCIS and invasive disease at 4 weeks, with evidence for further progression to invasive disease by 10 weeks (Figure 3F). This cumulative analysis shows time-dependent breast cancer progression through a DCIS stage, demonstrating the capacity of our xenograft model to serve as a tool to investigate human DCIS progression.

\section{Characterization of Myoepithelial Cells with DCIS Progression in Intraductal Model}

Loss of the myoepithelial cell layer is a hallmark of DCIS progression to invasive disease. ${ }^{9,10,36-39}$ However, the question of whether progressive loss of myoepithelial cell differentiation markers occurs before invasive disease has not been thoroughly investigated. Here, we used IHC to assess a panel of myoepithelial cell differentiation markers, $\alpha$-SMA, the major smooth muscle contractile protein; calponin, an actin-binding protein that regulates the power stroke during smooth muscle contraction $^{40,41}$; and p63, a transcription factor with putative tumor suppressor function. ${ }^{10,12,42}$ In non-tumor-bearing murine ducts, as expected, evidence was found for uniform myoepithelial cell expression of $\alpha$-SMA (Figure 4A), calponin (Figure 4B), and p63 (Figure 4C). However, even in DCISinvolved ducts with structural evidence of an intact myoepithelial cell layer, we observed variable expression of these myoepithelial cell markers (Figure 4, D-F). Evidence for additional loss in these markers occurred in DCIS-involved ducts with apparent microinvasion, as defined by the presence of small tumor cell clusters outside the confines of the duct (Figure 4, G-I). Quantification of these data shows that all three markers were expressed in most myoepithelial cells lining the normal ducts (Figure 4, J and K). However, in DCIS-involved ducts with a histologically-detected intact myoepithelial cell layer, at the 4-week time point $15 \%$ of the myoepithelium lacked $\alpha$-SMA, 30\% lacked calponin, and $92 \%$ lacked $p 63$ by IHC detection (Figure 4J), inferring differential loss of these markers within the myoepithelial cell. Further, coverage of calponin and $\alpha$-SMA was significantly decreased in DCIS with

\footnotetext{
Figure 5 Variable loss of myoepithelial cell differentiation markers in human breast cancer. Serial IHC analysis of myoepithelial cell markers $\alpha$-SMA (A and $\mathbf{D}$, brown) (red arrows depicts reactive fibroblast staining for $\alpha$-SMA), CALP (B and $\mathbf{E}$, brown), and p63 (C and $\mathbf{F}$, brown) shows high expression in myoepithelial cells surrounding some DCIS-involved ducts $(\mathbf{A}-\mathbf{C})$ and almost no expression in other lesions $(\mathbf{D}-\mathbf{F})$. Immunofluorescence staining of DCIS-involved ducts show differential expression of $\alpha$-SMA, CALP, and p63 in surrounding myoepithelial cells $(\mathbf{G}-\mathbf{N})$. Brightfield IHC signal quantification of myoepithelial cell $\alpha$-SMA, CALP, and p63 on 129 DCIS-involved ducts obtained from two cases of pure DCIS and three cases of invasive ductal carcinoma with DCIS (0). Immunofluorescent multiplex signal quantification of myoepithelial $\alpha$-SMA, CALP, and p63 on 105 DCIS-involved ducts from 14 cases with pure DCIS diagnoses (P). Myoepithelial cell expression of $\alpha$-SMA, CALP, and p63 vary between individual DCIS-involved ducts from the same case (Q). Statistical significance was determined by mixed effects analysis of variance and $P$ value justification for multiple comparisons using Tukey-Kramer approach. $* * * * P<0.0001$. Images were scanned with Aperio and Ariol software; digital resolution $=0.25 \mu \mathrm{m}$ per pixel $(\mathbf{A}-\mathbf{F}) ; 0.32 \mu \mathrm{m}$ per pixel $(\mathbf{G}-\mathbf{N})$. Scale bars: $30 \mu \mathrm{m}(\mathbf{A}-\mathbf{F}) ; 60 \mu \mathrm{m}(\mathbf{G}-\mathbf{N})$. CALP, calponin; DCIS, ductal carcinoma in situ; IHC, immunohistochemical; $\alpha$-SMA, $\alpha$-smooth muscle actin.
} 

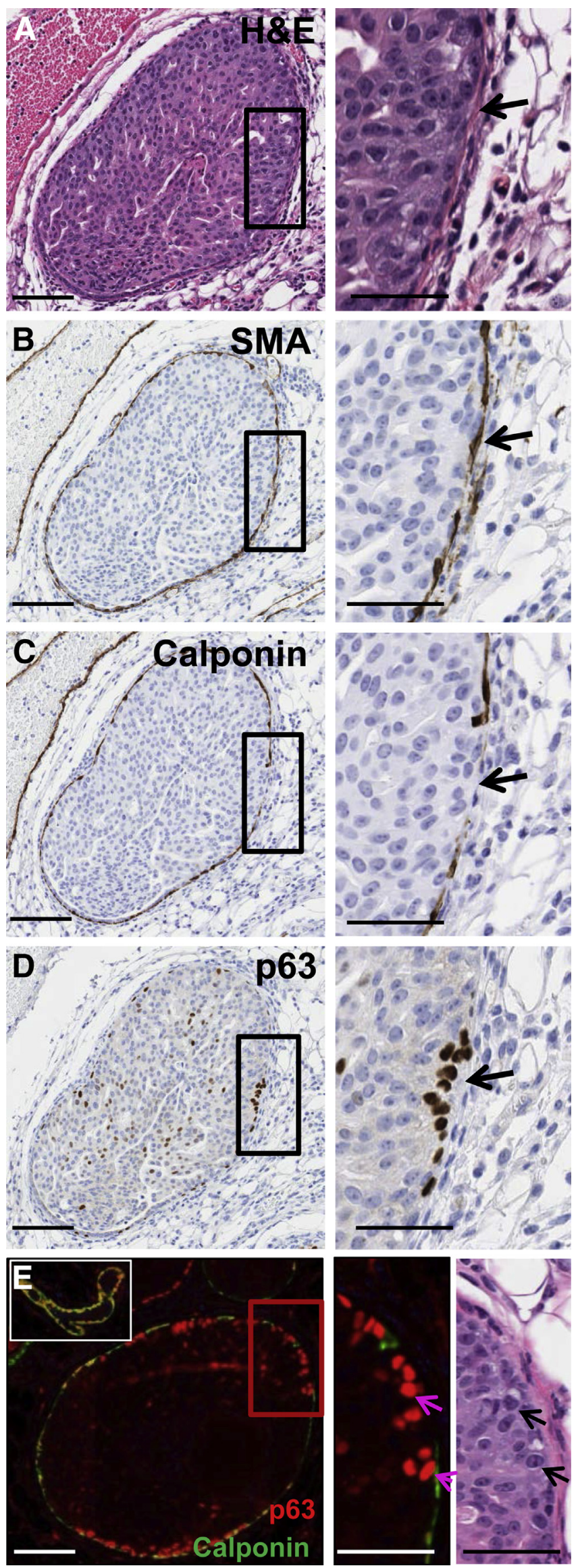

microinvasion (Figure 4J). Additional evidence to suggest that myoepithelial cell differentiation is compromised with DCIS progression was found at the 10-week time point, where marker coverage for $\alpha$-SMA and calponin showed trends toward decreased staining compared with the 4-week time point (Figure 4, J and K).

\section{Characterization of Myoepithelial Cells with DCIS Progression in Humans}

To determine whether similar trends in myoepithelial cell marker loss are observed in DCIS-involved ducts in women, five human cases, three with invasive ductal carcinoma with DCIS component and two with pure DCIS with a total of 172 DCIS-involved ducts identified by histologic review, were serially sectioned and singly stained for $\alpha$-SMA, calponin, and p63 expression. As observed in our mouse DCIS model, variable expression of these myoepithelial cell markers was observed; some human DCIS-involved myoepithelium displayed a high percentage of $\alpha$-SMA-, calponin-, and p63-positive cells (Figure 5, A-C) whereas others had variable or no expression of these markers (Figure 5, D-F). To confirm and expand these observations of marker loss within individual myoepithelial cells we performed multiplex immunofluorescence staining for all three markers in 16 cases of pure DCIS. This analysis confirmed colocalization of all three myoepithelial cell markers in uninvolved ducts (data not shown) and revealed similar trends for myoepithelial cell expression of $\alpha$-SMA, calponin, and p63 in DCISinvolved ducts (Figure 5, G-N). Quantitation of the five human cases stained for brightfield image analysis (Figure 5O) and the 14 pure DCIS cases stained for fluorescent image analysis (Figure 5P) showed trends in myoepithelial cell marker loss similar to that found in our intraductal mouse model with p63 expression less than calponin $(P<0.0001)$ and calponin expression less than $\alpha$-SMA $(P<0.0001)$. We also found myoepithelial cell expression of these three markers to vary between individual DCIS-involved ducts from the

Figure 6 Loss of myoepithelial cell calponin correlates with gain of p63 in adjacent tumor cells in the MCF10DCIS.com intraductal model. A representative DCIS lesion serially sectioned and stained by H\&E and by immunohistochemistry for $\alpha$-SMA, calponin, and p63 (A-D). Magnified insets on right show DCIS border with myoepithelial $\alpha$-SMA expression intact (B), myoepithelial calponin loss (C, black arrow), and gain of p63 in adjacent tumor cells (D, black arrow). Dual immunofluorescence staining for calponin (green) and p63 (red) shows representative DCIS lesion with variable myoepithelial cell calponin and $\mathrm{p} 63$ expression (E). A normal duct with co-localized myoepithelial cell p63 and calponin expression (yellow signal) serves as an internal positive control for dual staining myoepithelium (E, upper left inset). The epithelial cells comprising the normal duct are p63 negative. The magnified images of immunofluorescence and $\mathrm{H} \& \mathrm{E}$ staining on lower right show structural evidence of the tumor cells gaining p63 expression (arrows) coincident with loss of myoepithelial calponin. Images were scanned with Aperio and Ariol software; digital resolution $=0.25 \mu \mathrm{m}$ per pixel. Scale bars: $100 \mu \mathrm{m}$ (left); $50 \mu \mathrm{m}$ (right). DCIS, ductal carcinoma in situ; H\&E, hematoxylin and eosin; $\alpha$-SMA, $\alpha$-smooth muscle actin. 
Table 1 Intraductal Mouse Model Shows Loss of Myoepithelial Calponin Correlates with Gain of p63 in Adjacent Tumor Cells (Figure 6)

\begin{tabular}{|c|c|c|}
\hline Myoepithelial cell expression & $\begin{array}{l}\text { Adjacent } \\
\text { tumor } \\
\text { cells } \\
\text { expressing } \\
\text { p63, \% }\end{array}$ & $\begin{array}{l}\text { Myoepithelial- } \\
\text { adjacent } \\
\text { tumor } \\
\text { cell pairs } \\
\text { analyzed, } n\end{array}$ \\
\hline$\alpha^{\alpha-\text { SMA }^{+} \text {Calponin }^{+} \text {p63 }^{+}}$ & 0.2 & 519 \\
\hline$\alpha-$ SMA $^{+}$Calponin $^{+}$p63 $^{-}$ & 0.03 & 267 \\
\hline$\alpha-$ SMA $^{+}$Calponin $^{-}$p63 $^{-}$ & 27.2 & 154 \\
\hline
\end{tabular}

$\alpha$-SMA, $\alpha$-smooth muscle actin.

same case (Figure 5Q). Cumulatively, these data suggest sequential loss of expression of p63, calponin, and $\alpha$-SMA can occur in DCIS-involved ducts before overt loss of the myoepithelium and are consistent with the notion that myoepithelium cell function is compromised before the transition of noninvasive to invasive breast cancer.

With the use of our murine, intraductal DCIS model, we next investigated whether loss of the myoepithelial markers p63, calponin, or $\alpha$-SMA correlated with predicted markers of tumor cell progression. Loss of epithelial cell polarity contributes to acquisition of an invasive phenotype in models of human breast cancer ${ }^{43}$; thus, we evaluated the expression of GM130, a Golgi epithelial cell polarity marker whose expression is frequently lost in breast cancer. ${ }^{44}$ IHC analysis of GM130 did not show differences in localization between normal epithelium or DCIS tumor cells regardless of myoepithelial cell marker expression, nor were differences in E-cadherin staining observed (data not shown). However, IHC staining of calponin and p63 suggested an inverse relation between myoepithelial cell expression of calponin and gain of p63 expression in adjacent tumor cells (Figure 6, A-D). Dual immunofluorescence staining for calponin (green) and p63 (red) confirmed a striking correlation between loss of calponin expression in myoepithelial cells and gain of p63 expression in adjacent tumor cells in the MCF10DCIS.com intraductal model. Normal myoepithelial cells dual stain for both calponin and p63, and they serve as internal controls (Figure 6E). Within these normal ducts, the adjacent epithelium is p63 negative as expected. Further, at earlier time points, tumor cells within DCIS-involved ducts are p63 negative; whereas at 10 weeks after tumor cell injection, $27 \%$ of DCIS tumor cells adjacent to calponinnegative myoepithelial cells expressed p63 (Figure 6E and Table 1). This increase in tumor cell p63 expression in tumor cells adjacent to calponin-negative myoepithelium is approximately 130 -fold compared with tumor cells adjacent to calponin-positive myoepithelial cells (Figure 6E and Table 1). Of note, increases in tumor cell p63 expression were not observed when adjacent myoepithelium had lost p63 expression but retained calponin (Table 1). The gain of p63 expression in tumor cells suggests up-regulation of a basal cell differentiation pathway in response to calponin loss, data consistent with the transition of indolent tumor cells to a more invasive phenotype. . $^{4,46}$

\section{Discussion}

Our intraductal mouse model of human DCIS provides a rigorous approach to study early events in human breast cancer progression from DIN to breach of the myoepithelial cell layer. An intraductal approach described by Harrell et $\mathrm{al}^{47}$ also offers advancement, because this model supports lymph node metastasis. In their model, $200 \mu \mathrm{L}$ of tumor cells are deposited within the surgically exposed lactiferous duct. Our data, using epithelial cell tight junction disruption as a marker for loss of epithelial integrity, suggest that the normal ductal networks within the mammary gland of nulliparous mice are likely disrupted with injection volumes exceeding $10 \mu \mathrm{L}$. Thus larger-volume intraductal methods may not permit the investigation of early changes in the myoepithelial cell layer that occur with DCIS progression. Another published intraductal model injects a small volume of tumor cells into surgically exposed lactiferous ducts, thus preserving duct integrity. ${ }^{22,23}$ We find that similar surgical procedures induce localized wound-healing and inflammatory programs that have been shown to be tumor promotional in other contexts. ${ }^{28-31}$ Here, we describe a nonsurgical intraductal model that minimizes wound-healing programs and inflammation, which we propose may uniquely permit the evaluation of DCIS progression. A limitation to the method described here, and all human breast cancer mouse models, is the requirement for immune-deficient animals. The application of our intraductal approach to isogenic models would permit investigation of DCIS progression in an immune-competent host.

Our data demonstrate that DCIS-involved ducts with a physically intact myoepithelial cell layer can display progressive loss of specific myoepithelial cell markers and suggest that the myoepithelium is compromised before DCIS progression to overt invasive disease. We focused our studies on three myoepithelial cell markers: $\alpha$-SMA, calponin, and p63, loss of which are commonly used to identify DCIS progression to invasive disease in women. ${ }^{37-39}$ In our murine model, $\alpha$-SMA positivity surrounding DCIS-involved ducts remains relatively stable even at 10 weeks after intraductal injection (Figure $4 \mathrm{~K}$ ), suggesting that the actin cytoskeletal fibers are a stable feature of differentiated myoepithelial cells. However, gain of $\alpha$-SMA staining in adjacent cancerassociated fibroblasts limits the usefulness of $\alpha$-SMA in the diagnosis of DCIS. ${ }^{48,49}$ Calponin, an important actin-myosin regulator in smooth muscle cells, ${ }^{40,41}$ shows more frequent loss within myoepithelial cells, being largely present in lesions 4 weeks after injection and lost by 10 weeks after injection. Our data suggest that myoepithelial cell loss of calponin occurs before loss of $\alpha$-SMA, but after loss of p63, which occurs by 4 weeks after tumor cell injection in our murine model. A critical function of p63 is the development and maintenance of stratified epithelial tissue, including breast; $\mathrm{p} 63^{-1-}$ mice completely lack mammary epithelial tissue and $\mathrm{p} 63^{+/-}$mice 
are highly susceptible to spontaneous tumor formation in multiple organs. ${ }^{50}$ p63 is also an important regulator of terminal differentiation and polarity of both epidermal and myoepithelial cells, and disruption of these processes was shown to promote progression of DCIS to invasive cancers. ${ }^{5,51}$ In human breast DCIS-involved ducts, we found similar trends, with loss of p63 $>$ calponin $>\alpha$-SMA. These data are not consistent with experience of current clinical pathology, where losses of these myoepithelial cell markers are equated to absence of myoepithelial cells and thus progression to invasive disease.

The clinical focus on identifying areas of microinvasion, rather than correlation of multiple myoepithelial biomarkers as we have performed in this study, could hinder identification of myoepithelial cells that express a subset of markers. Further, our investigations into multiple myoepithelial cell markers in human DCIS was highly informed by data obtained from our preclinical model, where progressive loss of myoepithelial cell markers was observed over time in the context of a true time course study. The insight from our animal model facilitated investigation of differential loss of myoepithelial biomarkers in human DCIS. Further, our observations are not unprecedented, because previous publications have reported variable detection of the myoepithelial biomarkers $\alpha$-SMA, p63, and calponin within the same cells and interpreted the results as differential robustness of the IHC antibodies. ${ }^{37,52-55}$ Other studies have interpreted variable expression of myoepithelial biomarkers as evidence of injured myoepithelial cells, a conclusion similar to those we draw in our study. ${ }^{36,52,56}$

A limitation of our human DCIS study, in which myoepithelial markers were evaluated from single biopsy specimens, is the lack of time course data. Thus, it is only possible to infer progressive loss of p63 and calponin in $\alpha-\mathrm{SMA}^{+}$myoepithelium in women. Demonstration of progressive loss of myoepithelial cell markers will require sequential time point biopsies. Further, it is also important to evaluate myoepithelial cell marker integrity in the context of genomic and transcriptomic alterations. ${ }^{7}$

Surprisingly, in our mouse model of human DCIS, we found that myoepithelial cell loss of calponin correlated with gain of intratumoral p63 expression, whereas myoepithelial cell loss of p63 did not. Tumor cell expression of p63 indicates acquisition of basal-like attributes, and expression of other basal markers, including cytokeratin 5 and cytokeratin 14 , correlate with a more invasive phenotype ${ }^{57,58}$ Recently, it was shown that basal epithelial genes CK14 and p63 are required for collective invasion of breast tumor cells in three-dimensional cultures. ${ }^{46}$ Further, the predominant p63 isoform, $\delta N p 63 \alpha$, can function as an oncogene in epithelial cells. ${ }^{59}$ Collectively, these and other studies suggest that tumor cell acquisition of p63 within DCIS may support transition to invasive disease. Our preclinical data support a myoepithelial cell centric mechanism for DCIS progression whereby compromised myoepithelial cell function, possibly mediated through calponin loss, regulates the acquisition of p63 within adjacent tumor cells. Others have suggested that intratumoral p63 leads to subsequent decrease in p63 in myoepithelial cells, ${ }^{60,61}$ indicating bidirectional cross talk between myoepithelium and intraductal tumor cells contributes to DCIS progression.

The role of calponin in tumor progression remains poorly understood. Calponin is an integral component of $\alpha$-SMA where it regulates myosin binding to actin and modulates the power stroke during smooth muscle contraction. ${ }^{40,41}$ In addition, calponin has an identified signaling function, because calponin knockout results in $25 \%$ to $50 \%$ loss in actin gene expression in smooth muscle cells. ${ }^{40}$ Because both of these calponin-dependent functions are anticipated to contribute to structural integrity of the myoepithelium, calponin down-regulation is consistent with compromised myoepithelium and possible tumor cell escape. However, these identified smooth muscle functions of calponin do not readily explain the gain in p63 we observed in intraductal tumor cells adjacent to calponin-negative myoepithelial cells. Other calponin studies suggest tumor suppressive function. In a global gene expression study, the loss of calponin was identified as 1 of 17 genes that predicted risk of metastasis in patients diagnosed with small, stage I primary breast tumors. ${ }^{62}$ In human leiomyosarcoma, calponin inhibits signaling pathways important for cell growth, adhesion, and motility. ${ }^{63-65}$ Further, expression of calponin was shown to reduce tumorigenesis and cell motility in osteosarcoma, fibrosarcoma, aggressive adenocarcinoma, and melanoma cell lines. ${ }^{63}$ With further research efforts, expression of myoepithelial cell calponin may potentially serve as a useful marker for risk of DCIS progression and a therapeutic target for the prevention of DCIS progression to invasive cancer.

Our evidence that myoepithelial cells surrounding DCIS-involved ducts can lose expression of specific differentiation markers before overt invasion may provide insight into DCIS progression that could be harnessed for risk assessment. In the United States, approximately 1.6 million breast biopsies are performed each year, with 232,340 new cases of breast cancer and 64,640 cases of DCIS estimated in 2014 (American Cancer Society; http:// www.cancer.org/cancer/breastcancer/detailedguide/breastcancer-key-statistics, last accessed July 21, 2015). ${ }^{66,67}$ Approximately one-third of DCIS cases are predicted to progress to invasive disease if left untreated, highlighting their clinical significance ${ }^{68,69}$ To date, standard treatment for DCIS involves surgery, radiation, and/or chemotherapy, and there are no clinical tests to identify patients at high risk of developing invasive disease. Clinical use of specific risk biomarkers, possibly in combination with newly developed molecular tests, ${ }^{70}$ has the potential to balance either overtreatment or undertreatment of DCIS by improving individualized treatment options. With the use of our preclinical intraductal mouse model of human DCIS, we identified myoepithelial cell calponin expression as a candidate inhibitor 
of DCIS progression. The utility of myoepithelial calponin expression to serve as a risk marker for DCIS progression in women and a novel therapeutic target deserves further investigation.

\section{Acknowledgments}

We thank Dr. Peggy Neville (University of Colorado, Aurora, $\mathrm{CO}$ ) for guidance on intraductal tumor cell delivery; Dr. Jaime Fornetti (University of Colorado Cancer Center Cytogenetics Core and Division of Medical Oncology, Aurora, CO) for intraductal technique image acquisition; Dr. Marileila Garcia (University of Colorado Cancer Center Cytogenetics Core and Division of Medical Oncology) for FISH analysis; Patricia Bell for IHC assistance; the UCD Prostate Cancer Research Laboratory; and Troy Schedin for developing Aperio-based computational analyses; Ethan Cabral for CD45 image and data acquisition; Drs. Lisa Coussens, Takahiro Tsujikawa, and Sushil Kumar (Oregon Health \& Science University, Portland, OR) for multiplex immunofluorescent study support; the University of Colorado's Young Women's Breast Cancer Translational Program for providing access to clinical data and human tissue samples for this study; the patients for making their tissues available for research; and Drs. Carol Sartorius, Jennifer Richer, Jaime Fornetti, and Paul Jedlicka for critical manuscript review. MCF10DCIS.com cells and GFP-labeled MCF10DCIS.com cells were a generous gift from Fred Miller and Kornelia Polyak.

T.D.R. designed and performed all animal experiments and performed the intraductal injections, IHC, and ${ }^{14} \mathrm{C}$-sucrose experiments. S.J. designed human DCIS experiments, performed human tissue IHC, and designed and performed the multiplex immunofluorescent study. S.A. performed most IHC experiments and collected data. D.G. contributed to experimental design and conducted the statistical analyses. M.T. provided clinical annotation and clinical access to the pure DCIS cohort. V.F.B. provided access to human tissue and project oversight. P.S. conceptualized the study, supervised the project, and designed experiments. All authors provided critical review of data and data interpretation. T.D.R., S.J., and P.S. wrote the manuscript and M.T. and V.F.B. critically reviewed the manuscript.

\section{Supplemental Data}

Supplemental material for this article can be found at http://dx.doi.org/10.1016/j.ajpath.2015.07.004.

\section{References}

1. Wellings SR, Jensen HM: On the origin and progression of ductal carcinoma in the human breast. J Natl Cancer Inst 1973, 50: $1111-1118$

2. Yeang CH, McCormick F, Levine A: Combinatorial patterns of somatic gene mutations in cancer. FASEB J 2008, 22:2605-2622
3. Stephens PJ, Tarpey PS, Davies H, Van Loo P, Greenman C, Wedge DC, et al: The landscape of cancer genes and mutational processes in breast cancer. Nature 2012, 486:400-404

4. Ma XJ, Salunga R, Tuggle JT, Gaudet J, Enright E, McQuary P, Payette T, Pistone M, Stecker K, Zhang BM, Zhou YX, Varnholt H, Smith B, Gadd M, Chatfield E, Kessler J, Baer TM, Erlander MG, Sgroi DC: Gene expression profiles of human breast cancer progression. Proc Natl Acad Sci U S A 2003, 100: 5974-5979

5. Lee S, Stewart S, Nagtegaal I, Luo J, Wu Y, Colditz G, Medina D, Allred DC: Differentially expressed genes regulating the progression of ductal carcinoma in situ to invasive breast cancer. Cancer Res 2012, 72 : 4574-4586

6. Allinen M, Beroukhim R, Cai L, Brennan C, Lahti-Domenici J, Huang H, Porter D, Hu M, Chin L, Richardson A, Schnitt S, Sellers WR, Polyak K: Molecular characterization of the tumor microenvironment in breast cancer. Cancer Cell 2004, 6:17-32

7. Bombonati A, Sgroi DC: The molecular pathology of breast cancer progression. J Pathol 2011, 223:307-317

8. Moumen M, Chiche A, Cagnet S, Petit V, Raymond K, Faraldo MM, Deugnier MA, Glukhova MA: The mammary myoepithelial cell. Int J Dev Biol 2011, 55:763-771

9. Barsky SH, Karlin NJ: Myoepithelial cells: autocrine and paracrine suppressors of breast cancer progression. J Mammary Gland Biol Neoplasia 2005, 10:249-260

10. Hu M, Yao J, Carroll DK, Weremowicz S, Chen H, Carrasco D, Richardson A, Violette S, Nikolskaya T, Nikolsky Y, Bauerlein EL, Hahn WC, Gelman RS, Allred C, Bissell MJ, Schnitt S, Polyak K: Regulation of in situ to invasive breast carcinoma transition. Cancer Cell 2008, 13:394-406

11. Zou Z, Anisowicz A, Hendrix MJ, Thor A, Neveu M, Sheng S, Rafidi K, Seftor E, Sager R: Maspin, a serpin with tumor-suppressing activity in human mammary epithelial cells. Science 1994, 263: $526-529$

12. Barbareschi M, Pecciarini L, Cangi MG, Macri E, Rizzo A, Viale G, Doglioni C: p63, a p53 homologue, is a selective nuclear marker of myoepithelial cells of the human breast. Am J Surg Pathol 2001, 25: 1054-1060

13. Li JH, Man YG: Dual usages of single Wilms' tumor 1 immunohistochemistry in evaluation of breast tumors: a preliminary study of 30 cases. Cancer Biomark 2009, 5:109-116

14. Polyak K, Hu M: Do myoepithelial cells hold the key for breast tumor progression? J Mammary Gland Biol Neoplasia 2005, 10:231-247

15. Man YG, Sang QX: The significance of focal myoepithelial cell layer disruptions in human breast tumor invasion: a paradigm shift from the "protease-centered" hypothesis. Exp Cell Res 2004, 301:103-118

16. Sternlicht MD, Barsky SH: The myoepithelial defense: a host defense against cancer. Med Hypotheses 1997, 48:37-46

17. Zhang X, Hashemi SS, Yousefi M, Gao C, Sheng J, Ni J, Wang W, Mason J, Man YG: Atypical E-cadherin expression in cell clusters overlying focally disrupted mammary myoepithelial cell layers: implications for tumor cell motility and invasion. Pathol Res Pract 2009, 205:375-385

18. Man YG, Tai L, Barner R, Vang R, Saenger JS, Shekitka KM, Bratthauer GL, Wheeler DT, Liang CY, Vinh TN, Strauss BL: Cell clusters overlying focally disrupted mammary myoepithelial cell layers and adjacent cells within the same duct display different immunohistochemical and genetic features: implications for tumor progression and invasion. Breast Cancer Res 2003, 5: $\mathrm{R} 231-\mathrm{R} 241$

19. Nguyen D-AD, Beeman NG, Lewis MT, Schaack J, Neville MC: Intraductal injection into the mouse mammary gland. Edited by Ip MM, Asch BB. Methods in Mammary Gland Biology and Breast Cancer Research. New York, Kluwer Academic/Plenum, 2000, pp 259-270

20. Miller FR, Santner SJ, Tait L, Dawson PJ: MCF10DCIS.com xenograft model of human comedo ductal carcinoma in situ. J Natl Cancer Inst 2000, 92:1185-1186 
21. Russell TD, Fischer A, Beeman NE, Freed EF, Neville MC, Schaack J: Transduction of the mammary epithelium with adenovirus vectors in vivo. J Virol 2003, 77:5801-5809

22. Behbod F, Kittrell FS, Lamarca H, Edwards D, Kerbawy S, Heestand JC, Young E, Mukhopadhyay P, Yeh HW, Allred DC, Hu M, Polyak K, Rosen JM, Medina D: An intraductal human-inmouse transplantation model mimics the subtypes of ductal carcinoma in situ. Breast Cancer Res 2009, 11:R66

23. Medina D, Edwards DG, Kittrell F, Lee S, Allred DC: Intra-mammary ductal transplantation: a tool to study premalignant progression. J Mammary Gland Biol Neoplasia 2012, 17:131-133

24. Tavassoli FA: Ductal intraepithelial neoplasia of the breast. Virchows Arch 2001, 438:221-227

25. Pinder SE: Ductal carcinoma in situ (DCIS): pathological features, differential diagnosis, prognostic factors and specimen evaluation. Mod Pathol 2010, 23(Suppl 2):S8-S13

26. McDaniel SM, Rumer KK, Biroc SL, Metz RP, Singh M, Porter W, Schedin P: Remodeling of the mammary microenvironment after lactation promotes breast tumor cell metastasis. Am J Pathol 2006, 168:608-620

27. Qureshi A, Pervez S: Allred scoring for ER reporting and it's impact in clearly distinguishing ER negative from ER positive breast cancers. J Pak Med Assoc 2010, 60:350-353

28. Martins-Green M, Boudreau N, Bissell MJ: Inflammation is responsible for the development of wound-induced tumors in chickens infected with Rous sarcoma virus. Cancer Res 1994, 54:4334-4341

29. Coussens LM, Werb Z: Inflammation and cancer. Nature 2002, 420: 860-867

30. Schafer M, Werner S: Cancer as an overhealing wound: an old hypothesis revisited. Nat Rev Mol Cell Biol 2008, 9:628-638

31. Stuelten CH, Barbul A, Busch JI, Sutton E, Katz R, Sato M, Wakefield LM, Roberts AB, Niederhuber JE: Acute wounds accelerate tumorigenesis by a $\mathrm{T}$ cell-dependent mechanism. Cancer Res 2008, 68:7278-7282

32. Nguyen DA, Neville MC: Tight junction regulation in the mammary gland. J Mammary Gland Biol Neoplasia 1998, 3:233-246

33. Neve RM, Chin K, Fridlyand J, Yeh J, Baehner FL, Fevr T, Clark L, Bayani N, Coppe JP, Tong F, Speed T, Spellman PT, DeVries S, Lapuk A, Wang NJ, Kuo WL, Stilwell JL, Pinkel D, Albertson DG, Waldman FM, McCormick F, Dickson RB, Johnson MD, Lippman M, Ethier S, Gazdar A, Gray JW: A collection of breast cancer cell lines for the study of functionally distinct cancer subtypes. Cancer Cell 2006, 10:515-527

34. Shekhar MP, Tait L, Pauley RJ, Wu GS, Santner SJ, NangiaMakker P, Shekhar V, Nassar H, Visscher DW, Heppner GH, Miller FR: Comedo-ductal carcinoma in situ: a paradoxical role for programmed cell death. Cancer Biol Ther 2008, 7:1774-1782

35. Lyons TR, O'Brien J, Borges VF, Conklin MW, Keely PJ, Eliceiri KW, Marusyk A, Tan AC, Schedin P: Postpartum mammary gland involution drives progression of ductal carcinoma in situ through collagen and COX-2. Nat Med 2011, 17:1109-1115

36. Man YG: Focal degeneration of aged or injured myoepithelial cells and the resultant auto-immunoreactions are trigger factors for breast tumor invasion. Med Hypotheses 2007, 69:1340-1357

37. Hilson JB, Schnitt SJ, Collins LC: Phenotypic alterations in ductal carcinoma in situ-associated myoepithelial cells: biologic and diagnostic implications. Am J Surg Pathol 2009, 33:227-232

38. Bhargava R, Dabbs DJ: Use of immunohistochemistry in diagnosis of breast epithelial lesions. Adv Anat Pathol 2007, 14: 93-107

39. Lerwill MF: Current practical applications of diagnostic immunohistochemistry in breast pathology. Am J Surg Pathol 2004, 28: 1076-1091

40. Matthew JD, Khromov AS, McDuffie MJ, Somlyo AV, Somlyo AP, Taniguchi S, Takahashi K: Contractile properties and proteins of smooth muscles of a calponin knockout mouse. J Physiol 2000, 529(Pt 3):811-824
41. Haeberle JR: Calponin decreases the rate of cross-bridge cycling and increases maximum force production by smooth muscle myosin in an in vitro motility assay. J Biol Chem 1994, 269:12424-12431

42. Reis-Filho JS, Schmitt FC: Taking advantage of basic research: p63 is a reliable myoepithelial and stem cell marker. Adv Anat Pathol 2002, 9:280-289

43. Feigin ME, Muthuswamy SK: Polarity proteins regulate mammalian cell-cell junctions and cancer pathogenesis. Curr Opin Cell Biol 2009, 21:694-700

44. Baschieri F, Confalonieri S, Bertalot G, Di Fiore PP, Dietmaier W, Leist M, Crespo P, Macara IG, Farhan H: Spatial control of Cdc42 signalling by a GM130-RasGRF complex regulates polarity and tumorigenesis. Nat Commun 2014, 5:4839

45. Sorlie T, Perou CM, Tibshirani R, Aas T, Geisler S, Johnsen H, Hastie T, Eisen MB, van de Rijn M, Jeffrey SS, Thorsen T, Quist H, Matese JC, Brown PO, Botstein D, Lonning PE, Borresen-Dale AL: Gene expression patterns of breast carcinomas distinguish tumor subclasses with clinical implications. Proc Natl Acad Sci U S A 2001, 98:10869-10874

46. Cheung KJ, Gabrielson E, Werb Z, Ewald AJ: Collective invasion in breast cancer requires a conserved basal epithelial program. Cell 2013, 155:1639-1651

47. Harrell JC, Dye WW, Harvell DM, Pinto M, Jedlicka P, Sartorius CA, Horwitz KB: Estrogen insensitivity in a model of estrogen receptor positive breast cancer lymph node metastasis. Cancer Res 2007, 67: 10582-10591

48. Walker RA, Hanby A, Pinder SE, Thomas J, Ellis IO; National Coordinating Committee for Breast Pathology Research Subgroup: Current issues in diagnostic breast pathology. J Clin Pathol 2012, 65: $771-785$

49. Hua X, Yu L, Huang X, Liao Z, Xian Q: Expression and role of fibroblast activation protein-alpha in microinvasive breast carcinoma. Diagn Pathol 2011, 6:111

50. Flores ER, Sengupta S, Miller JB, Newman JJ, Bronson R, Crowley D, Yang A, McKeon F, Jacks T: Tumor predisposition in mice mutant for $\mathrm{p} 63$ and p73: evidence for broader tumor suppressor functions for the p53 family. Cancer Cell 2005, 7:363-373

51. Hu M, Polyak K: Molecular characterisation of the tumour microenvironment in breast cancer. Eur J Cancer 2008, 44:2760-2765

52. Dewar R, Fadare O, Gilmore H, Gown AM: Best practices in diagnostic immunohistochemistry: myoepithelial markers in breast pathology. Arch Pathol Lab Med 2011, 135:422-429

53. Cserni G: Benign apocrine papillary lesions of the breast lacking or virtually lacking myoepithelial cells-potential pitfalls in diagnosing malignancy. APMIS 2012, 120:249-252

54. Kawaguchi K, Shin SJ: Immunohistochemical staining characteristics of low-grade adenosquamous carcinoma of the breast. Am J Surg Pathol 2012, 36:1009-1020

55. Werling RW, Hwang H, Yaziji H, Gown AM: Immunohistochemical distinction of invasive from noninvasive breast lesions: a comparative study of p63 versus calponin and smooth muscle myosin heavy chain. Am J Surg Pathol 2003, 27:82-90

56. Xu Z, Wang W, Deng CX, Man YG: Aberrant p63 and WT-1 expression in myoepithelial cells of pregnancy-associated breast cancer: implications for tumor aggressiveness and invasiveness. Int $\mathrm{J}$ Biol Sci 2009, 5:82-96

57. Malzahn K, Mitze M, Thoenes M, Moll R: Biological and prognostic significance of stratified epithelial cytokeratins in infiltrating ductal breast carcinomas. Virchows Arch 1998, 433:119-129

58. Gusterson BA, Ross DT, Heath VJ, Stein T: Basal cytokeratins and their relationship to the cellular origin and functional classification of breast cancer. Breast Cancer Res 2005, 7:143-148

59. Keyes WM, Pecoraro M, Aranda V, Vernersson-Lindahl E, Li W, Vogel H, Guo X, Garcia EL, Michurina TV, Enikolopov G, Muthuswamy SK, Mills AA: DeltaNp63alpha is an oncogene that targets chromatin remodeler Lsh to drive skin stem cell proliferation and tumorigenesis. Cell Stem Cell 2011, 8:164-176 
60. Stefanou D, Batistatou A, Nonni A, Arkoumani E, Agnantis NJ: p63 expression in benign and malignant breast lesions. Histol Histopathol 2004, 19:465-471

61. Shekhar MP, Kato I, Nangia-Makker P, Tait L: Comedo-DCIS is a precursor lesion for basal-like breast carcinoma: identification of a novel p63/Her2/neu expressing subgroup. Oncotarget 2013, 4:231-241

62. Ramaswamy S, Ross KN, Lander ES, Golub TR: A molecular signature of metastasis in primary solid tumors. Nat Genet 2003, 33:49-54

63. Rozenblum GT, Gimona M: Calponins: adaptable modular regulators of the actin cytoskeleton. Int J Biochem Cell Biol 2008, 40: 1990-1995

64. Hayashi T, Horiuchi A, Sano K, Hiraoka N, Kasai M, Ichimura T, Sudo T, Nishimura R, Ishiko O, Shiozawa T, Kanai Y, Yaegashi N, Aburatani H, Konishi I: Potential role of LMP2 as an anti-oncogenic factor in human uterine leiomyosarcoma: morphological significance of calponin h1. FEBS Lett 2012, 586:1824-1831

65. Lener T, Burgstaller G, Gimona M: The role of calponin in the gene profile of metastatic cells: inhibition of metastatic cell motility by multiple calponin repeats. FEBS Lett 2004, 556:221-226
66. Siegel R, Ma J, Zou Z, Jemal A: Cancer statistics, 2014. CA Cancer J Clin 2014, 64:9-29

67. Silverstein MJ, Recht A, Lagios MD, Bleiweiss IJ, Blumencranz PW, Gizienski T, Harms SE, Harness J, Jackman RJ, Klimberg VS, Kuske R, Levine GM, Linver MN, Rafferty EA, Rugo H, Schilling K, Tripathy D, Vicini FA, Whitworth PW, Willey SC: Special report: consensus conference III. Image-detected breast cancer: state-of-the-art diagnosis and treatment. J Am Coll Surg 2009, 209:504-520

68. American Cancer Society, Cancer Facts and Figures. Atlanta, GA, American Cancer Society, 2013

69. Allred DC: Ductal carcinoma in situ: terminology, classification, and natural history. J Natl Cancer Inst Monogr 2010, 2010: 134-138

70. Solin LJ, Gray R, Baehner FL, Butler SM, Hughes LL, Yoshizawa C, Cherbavaz DB, Shak S, Page DL, Sledge GW Jr, Davidson NE, Ingle JN, Perez EA, Wood WC, Sparano JA, Badve S: A multigene expression assay to predict local recurrence risk for ductal carcinoma in situ of the breast. J Natl Cancer Inst 2013, 105:701-710 